\title{
THE USE OF SOCIAL NETWORKING SITES: THE INTERPLAY BETWEEN SCHOOL BURNOUT LEVELS AND FRIENDSHIP QUALITY IN ADOLESCENCE
}

\author{
Simona De Stasio \\ Libera Università Maria SS. Assunta \\ Dipartimento di Scienze Umane, Roma \\ s.destasio@lumsa.it \\ Benedetta Ragni \\ Libera Università Maria SS. Assunta \\ Dipartimento di Scienze Umane, Roma \\ Eliana Bucchi \\ Libera Università Maria SS. Assunta \\ Dipartimento di Scienze Umane, Roma \\ Giulia Altea \\ Libera Università Maria SS. Assunta \\ Dipartimento di Scienze Umane, Roma \\ Chiara Bacile \\ Libera Università Maria SS. Assunta \\ Dipartimento di Scienze Umane, Roma
}

Fecha de Recepción: 20 Agosto 2019

Fecha de Admisión: 25 Septiembre 2019

\begin{abstract}
Main purposes of our study were to explore: a) the relationships between massive use of Social Networks sites (SNs) in adolescence, school burnout levels and friendship quality; b) gender differences in massive and problematic use of SNs.

110 Italian high school students $(M=69,9 \%)$ aged 15-17 years participated in the study. Students were asked to complete self-report questionnaires: an ad-hoc scale for investigating SNs use, The Generalized Pathological Internet Use Scale-2 (GPIUS-2; Caplan, 2010), The Parent and Peer attachment inventory for Friendship Quality (Armsden \& Greenberg, 1987), The School Burnout Inventory (SBI; Samlela-Aro et al., 2009).

Results showed positive relationships between massive SNs use and friendship quality $(r=.30$, $p<.01)$; compulsive SNs (GPIUS-2) use and school burnout total score $(r=.25, p<.01)$; massive SNs use and female gender $(r=.17, p<.05)$, and finally a positive relationship between SNs use for mood regulation and school burnout total score $(r=.20, p<.05)$. Moreover, significant difference emerged between females and males in SNs massive use, with higher levels reported by females $(M=23.55, D S=3.614)$ in comparison to males $(M=21.89, D S=4.261) ; t(138)=-2.13, p=.035$.
\end{abstract}




\section{THE USE OF SOCIAL NETWORKING SITES: THE INTERPLAY BETWEEN SCHOOL BURNOUT LEVELS AND FRIENDSHIP QUALITY IN ADOLESCENCE}

Overall, this study highlights different dimensions that could influence SNs massive and problematic use in adolescence, specifically school burnout and friendship quality. Structuring interventions in order to promote socio-relational skills among peers and to prevent school-related burnout could prevent problematic use of SNs in adolescence.

Keywords: social networks; school burnout; friendship quality; adolescence; compulsive use.

\section{INTRODUCTION}

Using social networks sites (SNs) in adolescence has been reported to be one of the most frequent Internet activity (Cerrato, Martin-Perpina \& Vinas-Poch, 2018; Subrahmanyam \& Greenfield, 2008) and over the years, the Internet and SNs have become an essential social context for adolescents. While there have been positive outcomes associated with SNs use, such as new opportunities for sociability, there were also be negative ones: research has shown that some adolescents tend to use Internet and SNs excessively or in a maladaptive way with negative consequences on different aspects of their life, such as school, relations with parents and peers and their psychological wellbeing (Ballarotto et al., 2018; Livingstone et al., 2011).Literature underlines that, in adolescence, girls show higher levels of massive Internet use than male peers, showing in association both higher levels of internalization and externalization problems. They also spend more time on SNs than boys and seem more interested in the relational aspects of SNs (Anderson, Steen \& Stravropoulos, 2016). In this regard, studies show that girls use SNs primarily to seek closer and more intimate relationships with their peers, to share emotions and personal problems, to keep in touch with peers from their offline lives and with friends they rarely see, to reinforce friendships, and to make plans with friends; on the other hand, boys reported using SNs to flirt and make new friends and are more interested in playing online games (Ballarotto et al., 2018).In adolescence, SNs' use leads at searching for autonomy, intimacy, identity and socialization (Borca et al., 2015). Specifically, communication with peers resulted a primary function of SNs. Studies showed that adolescents have a broader online friendship network than offline, although the majority of them perceived these online relationships as unsubstantial (Espinoza \& Juvonen, 2011). Starting an online friendship exposes to fewer risks considering the possibility of asynchronous and anonymous online communications (Buote, Wood \& Pratt, 2009). SNs could help in strengthening existing friendships, allowing adolescents to communicate with peers in a context where they appear more comfortable in sharing their feelings (Borca et al., 2015). For these reasons, online communication is perceived by adolescents as more effective than offline communication, also contributing to increasing perceived reciprocal confidence among peers (Valkenburg \& Peter, 2007).During adolescence, pressures of schoolwork and responsibilities could affect students' stress levels, and this stress could result in burnout syndrome (Walburg, Mialhes \& Moncla, 2016). Specifically, school-related burnout includes three significant dimensions: exhaustion at school, cynicism toward the meaning of school, and a sense of inadequacy at school (Salmela-Aro et al., 2009). High levels of school burnout seem to be associated with lower levels of school engagement and academic achievement (Salmela-Aro, Kiuru \& Jokela, 2008). Moreover, school burnout could also be the result of a discrepancy between school expectations and high standards, and their real school results (Kiuru, et al., 2008). For this reason, it could be possible that the students with higher levels of burnout would perceive a gap between whom they want to be and who they are with a consequent desire to escape from themselves, using, for example, SNs (Walburg, Mialhes \& Moncla, 2016). Considering that SNs are particularly prevalent among adolescents, it could be interesting focusing on how stress situations such as school-related burnout could influence the massive use of SNs. The main aim of this study was to explore, in a group of adolescents, the relationships among SNs massive use, friendship quality and school burnout levels, in order to investigate risk and protective factors associated with a maladaptive use of SNs. 


\section{MATERIAL AND METHODS}

110 Italian high school students $(M=69,9 \%)$ aged 15-17 years participated in the study. Considering the use of SNs, $82.1 \%$ of students used Instagram, and only $15 \%$ used Facebook. Furthermore, 2.9\% reported not to use SNs but the only Internet. Students were asked to complete self-report questionnaires: An ad-hoc scale for investigating SNs use; the questionnaire was composed by seven items measured on a five-point Likert-scale $(1=$ I never use it for this reason; $5=1$ always use it for this reason). Higher scores indicate massive SNs use. The Generalized Pathological Internet Use Scale-2 (GPIUS-2; Caplan, 2010); students' pathological Internet and SNs use were assessed with this 15 items-questionnaire, measured on a five-point Likert-scale (1=completely disagree; 5=completely agree). For this study, two subscales were used: Mood regulation and Compulsive Use. The Parent and Peer attachment inventory for Friendship Quality (Armsden \& Greenberg, 1987); four items from the inventory were selected for this study to measure adolescents' closeness to friends (Valkenburg \& Peter, 2007) items were measured by a five-point Likertscale ( $1=$ completely disagree; $5=$ completely agree). The selected items were "When my friends know that something is bothering me, they ask me about it," "I tell my friends about my problems and troubles," "My friends help me to understand myself better," and "When I am angry about something, my friends try to be understanding.". The School Burnout Inventory (SBI; Fiorilli et al., 2014; Samlela-Aro et al., 2009) assessed students' school burnout, and it is composed of nine items rated on a 6 -points Likert scale ( $1=$ completely disagree; $6=$ completely agree). Higher scores indicate high school burnout.

\section{RESULTS}

Intercorrelations among studied variables were measured by bivariate Pearson correlations and are displayed in Table 1. Results showed positive relationships between massive SNs use and friendship quality $(r=.30, p<.01)$; compulsive SNs (GPIUS-2) use and school burnout total score $(r=$ $.25, p<.01)$; massive SNs use and female gender $(r=.17, p<.05)$, and finally a positive relationship between SNs use for mood regulation and school burnout total score $(r=.20, p<.05)$.An independent $t$-test was performed in order to investigate gender differences in SNs massive use. Results, displayed in Table 2, showed a significant difference between females and males in SNs massive use, with higher levels reported by females $(M=23.55, D S=3.614)$ in comparison to males $(M=21.89$, $\mathrm{DS}=4.261) ; \mathrm{t}(138)=-2.13, \mathrm{p}=.035$. Moreover, females reported higher levels of total school burnout $\left(\mathrm{M}_{\mathrm{female}}=3.28, \mathrm{DS}=1.041 ; \mathrm{M}_{\mathrm{male}}=2.78, \mathrm{DS}=1.048\right) ; \mathrm{t}(138)=-2.04, \mathrm{p}=.044$.

Table 1. Bivariate correlations among studied variables

\begin{tabular}{llllllll}
\hline & 1 & 2 & 3 & 4 & 5 & 6 & 7 \\
\hline 1.Massive SNs use & 1 & & & & & & \\
2.Mood regulation & $.40^{* *}$ & 1 & & & & & \\
3.Friendship quality & $.30^{* *}$ & .15 & 1 & & & & \\
4.Compulsive use & $.39^{* *}$ & $.42^{* *}$ & -.12 & 1 & & & \\
5.School Burnout & .10 & $.20^{*}$ & -.01 & $.25^{* *}$ & 1 & & \\
6.Gender & $.17^{*}$ & .01 & $.27^{* *}$ & .09 & $.17^{*}$ & 1 & \\
7.Age & .13 & -.03 & .11 & -.02 & -.07 & -.13 & 1 \\
\hline
\end{tabular}

SNs (Social Network sites); ${ }^{* *} p<.01 ; * p<.05$ 
THE USE OF SOCIAL NETWORKING SITES: THE INTERPLAY BETWEEN SCHOOL BURNOUT LEVELS AND FRIENDSHIP QUALITY IN ADOLESCENCE

Table 2. $t$-test results comparing males and females on studied variables

\begin{tabular}{lccccc}
\hline \multirow{2}{*}{ Variables } & $\begin{array}{l}\text { Males } \\
(\mathrm{N}=98)\end{array}$ & \multicolumn{3}{c}{$\begin{array}{l}\text { Females } \\
(\mathrm{N}=22)\end{array}$} & \multirow{2}{*}{-test } \\
\cline { 2 - 6 } & $\mathbf{M}$ & SD & $\mathbf{M}$ & SD & P \\
\hline Massive SNs use & 21.89 & 4.26 & 23.55 & 3.61 & $.035^{*}$ \\
Mood regulation & 1.88 & .92 & 1.89 & .74 & .933 \\
Compulsive use & 1.95 & .84 & 2.13 & .75 & .262 \\
School Burnout & 2.78 & 1.04 & 3.18 & 1.04 & $.044^{*}$ \\
\hline${ }_{p} p 05$ & & & & &
\end{tabular}

\section{DISCUSSION}

The main aim of this study was to investigate, in a group of adolescents, existing relationships among SNs massive and problematic use, school burnout levels and friendship quality. Literature underlines significant associations between school burnout and problematic use of the Internet in adolescence (Salmela-Aro et al., 2017). From our results emerged a significant positive association between adolescents' perceived school burnout and problematic SNs use: the more adolescents reported higher levels of burn-out, the more they massively use SNs. According to literature (Walburg, Mialhes \& Moncla, 2016) higher levels of school-related stress perceived by students could induce them to use SNs, perceived as more reassuring and comfortable, in order to escape from reality. Moreover, from our results emerged a significant positive association between SNs massive use and perceived friendship quality: the more adolescents perceive their friendships as supportive, the more they report using SNs. These results are in line with the literature (Espinoza \& Juvonen, 2011; Borca et al. 2015). Some adolescents may use SNs in order to strengthen their friendships, perceiving online communication as deeper and close. Online emotional disclosure is perceived as more intimate and comfortable by adolescents and, for this reason, online communication as more effective than the offline (Valkenburg \& Peter, 2007). When adolescents have an offline friendship network in which experience feelings of affiliation and trust, a higher SNs use will help them in maintaining closeness and support with the group (Espinoza \& Juvonen, 2011). Finally, considering gender differences, our results underlined how girls reported higher massive use of SNs the boys. These data are in line with the literature (Anderson, Steen \& Stravropoulos, 2016) and specifically, recent studies highlighted that girls, in comparison to boys, use SNs searching for more intimate and close relationships in order to share emotional and personal problems (Ballarotto et al., 2018).

This study has potential limitations. First, our sample was mainly composed by males' adolescents, consequently more heterogeneous samples should be used to test the generalizability of these findings in future investigations. Moreover, this research has a cross-sectional design and therefore it is not possible to draw causal inferences about relationships among variables; further longitudinal researchers are needed to examine and understand these relationships over time.

\section{CONCLUSIONS}

Overall, this study highlights different dimensions that could influence SNs massive and problematic use in adolescence, specifically school burnout and friendship quality. Structuring interventions in order to promote socio-relational skills among peers and to prevent school-related burnout could prevent problematic use of SNs in adolescence. 


\section{BIBLIOGRAPHIC REFERENCES}

Anderson, E.L, Steen, E. \& Stavropoulos, V., 2016. Internet use and problematic internet use: a systematic review of longitudinal research trends in adolescence and emergent adulthood. International Journal of adolescence and youth, 22 (4), pp. 430-454.

Armsden, G. C. \& Greenberg, M. T., 1987. The inventory of parent and peer attachment: individual differences and their relationship to psychological well-being in adolescence. Journal of Youth and Adolescence,16 (5), pp. 427-454.

Ballarotto, G., Volpi, B., Marzilli, E. \& Tambelli, R., 2018. Adolescent internet abuse: a study on the role of attachment to parents and peer in a large community sample. BioMed research international, 14, pp. 1-10.

Borca ${ }_{\perp}$ G., Bina, M., Keller, P., Gilbert L. R. \& Begotti, T., 2015. Internet use and developmental tasks: Adolescents' point of view. Computers in Human Behavior,52, pp. 49-58.

Buote, V. M., Wood, E. \& Pratt, M., 2009. Exploring similarities and differences between online and offline friendships: the role of attachment style. Computer and Human Behavior, 25 (2), pp.560567.

Caplan, S. E., 2010. Theory and measurement of generalized problematic Internet use: A two-step approach. Computers in Human Behavior, 26 (5), pp. 1089-1097.

Cerrato, M. S., Martin-Perpina, M. M. \& Vinas-Poch, F., 2018. Excessive use of social network: psychosocial profile of spanish adolescents. Media educational research journal, 56(26), pp.101109.

Espinoza, G. M. A. \& Juvonen, J., 2011. The pervasiveness, connectedness, and intrusiveness of social network site use among young adolescents. Cyberpsichology, behavior,and social networking, 14 (12), pp.705-709.

Fiorilli, C., Galimberti, V., De Stasio, S., Di Chiaccio, C. \& Albanese, 0., 2014. L'utilizzazione dello School Burnout Inventory(SBI) con studenti italiani di scuola superiore di primo e secondo grado. Psicologia clinica dello sviluppo, 18 (3), pp.403-423.

Kiuru, N., Aunola, K., Nurmi, J. E., Leskinen, E. \& Salmela-Aro, K., 2008. Peer Group Influence and Selection in Adolescent's School Burnout. Merrill-Palmer Quarterly, 54 (1), pp. 23-55.

Livingstone, S., Haddon, L., Görzig, A. \& Ólafsson, K., 2011. Risks and safety on the Internet: The perspective of European children: full findings and policy implications from the EU Kids Online survey of 9-16 year olds and their parents in 25 countries.

Salmela-Aro K., Kiuru, N. \& Jokela, J., 2008. Does school matter? The role of school context in adolescents' school-related burnout. European Psychologist, 13(1), pp. 12-23.

Salmela-Aro, K., Kiuru, N., Leskinen, E. \& Nurmi, J., 2009. School Burnout Inventory (SBI) Reliability and Validity. European Journal of Psychological Assessment, 25, pp. 48-57.

Salmela-Aro, K., Upadyaya, K., Hakkarainen, K., Lonka, K. \& Alho, K., 2017. The Dark Side of Internet Use: Two Longitudinal Studies of Excessive Internet Use, Depressive Symptoms, School Burnout and Engagement Among Finnish Early and Late Adolescents. Journal of Youth and Adolescence, 46 (2), pp. 343-357.

Subrahmanyam, K. \& Greenfield, P. M., 2008). Communicating online: Adolescence relationships and the media. The Future of Children, 18, pp. 119-146.

Valkenburg, P. M. \& Peter, J., 2007. Preadolescent's and Adolescent's online communication and their closeness to friends. Developmental Psychology, 43 (2), pp. 267-277.

Walburg, V., Mialhes, A. \& Moncla, D., 2016. Does school-related burnout influence problematic Facebook use?, Children and Youth Services Review, 61, pp.327-331. 
